\title{
Anterior Cervical Discectomy and Fusion (ACDF) using Stand- Alone Polyetheretherketone (PEEK) Cage Packed with Local Autologous Bone Graft
}

\author{
Mohammad Nuruzzaman Khan ${ }^{1 *}$, Sabrina Shafiq ${ }^{2}$, Saumitra Sarkar ${ }^{1}$ \\ ${ }^{1}$ Assistant Professor, Department of Neurosurgery, Shaheed Suhrawardy Medical College Hospital, Dhaka, \\ Bangladesh \\ ${ }^{2}$ Resident, Department of Laboratory Medicine, Bangabandhu Sheikh Mujib Medical University, Dhaka, \\ Bangladesh \\ ${ }^{3}$ Associate Professor, Department of Neurosurgery, Shaheed Suhrawardy Medical College Hospital, Dhaka, \\ Bangladesh
}

*Corresponding Author: Mohammad Nuruzzaman Khan, Assistant Professor, Department of Neurosurgery, Shaheed Suhrawardy Medical College Hospital, Dhaka, Bangladesh, Email: drkhosru71@yahoo.com

\begin{abstract}
Introduction: It remains debatable that whether the cages should be filled with any type of bone or bone substitute in anterior cervical discectomy and fusion $(A C D F)$ surgery. To fill the cage, the anterior and posterior osteophytes of the adjacent upper and lower vertebra could be used. The aims of the present study was to find out the clinical and radiological outcomes which includes bony fusion and subsidence after ACDF surgery with a stand-alone polyetheretherketone (PEEK) cage filled with local autologous bone from adjacent vertebral body.
\end{abstract}

Methods: All of the thirty six consecutive patients underwent ACDF surgery with a stand-alone polyetheretherketone cage filled with local autologous bone graft from July 2015 to June 2017 were included in the present study. Subsidence (the interbody height decreased $\geq 2 \mathrm{~mm}$ ) and Bone fusion were evaluated by cervical plain radiographs.

Results: Subsidence (the inter body height decreased $\geq 2 \mathrm{~mm}$ ) was found in 9 patients (25\%). Among the nine patients of subsidence group, nonunion was found in five patients. Out of nine patients with subsidence, endplate was damaged in four patients during intraoperative preparation of endplate. Thirty one patients $(86.11 \%)$ achieved solid bone fusion

Conclusion: In selected patients with adequate and careful preparation of endplate, ACDF surgery using a stand-alone polyetheretherketone (PEEK) cage filled with local autologous bone could be a good alternative of anterior cervical discectomy and fusion (ACDF) with iliac crest bone graft or bone substitute with or without plating.

Keywords: Anterior Cervical Discectomy and Fusion, Polyetheretherketone Cage, Local autologous bone.

\section{INTRODUCTION}

Cervical spine degenerates with age and degenerated disc of cervical spine may cause neck pain, radiating arm pain or cervical myelopathy. The gold standard treatment for the patients having cervical radiculopathy and myelopathy is anterior cervical discectomy and fusion (ACDF). This technique has been modified many times since the discovery of this procedure by Smith and Robinson ${ }^{1,2,3,4}$.

Earlier autologous the iliac crest bone was used to fill the disc space to maintain the interbody height and fusion with or without supplemented by cervical plating. There are several advantages of cervical plate system, but it has risk of hardware failure, high additional costs, adjacent level disc degeneration and questionable of necessity to use in absence of instability ${ }^{5,6}$. Moreover numerous complications results from autologous tricortical iliac crest bone graft including protrusion of bone block, breaking of bone graft, subsidence, collapsing, angular deformation, pseudo arthrosis ${ }^{7}$. To overcome these complications, it is replaced by standalone case packed with autologous iliac crest bone graft, however, it causes a number of donor site morbidities including infection, pain 
and numbness ${ }^{8,9}$. To avoid these complications, bone substitutes or allobone have been used. The risk of bone substitutes and allobone are low fusion rate, chance of pathogen transmission and high additional costs ${ }^{5,10,11}$. In ACDF surgery some surgeons have used an empty cage. But due to the suspicion of low bone fusion rate, they could not reached a general agreement ${ }^{10,11}$. Recently, few studies showed a favorable results of anterior cervical discectomy and fusion (ACDF)with a standalone cage filled with local autologous bone graft ${ }^{2,4,8}$. Park et al. ${ }^{12}$ and Shad et al. ${ }^{13}$ described that ACDF with a local autologous bone graft filled stand-alone cage has good radiological and clinical outcomes without any high additional costs and iliac bone donor site morbidity. However, the complications of this procedure have been reported as subsidence and nonunion ${ }^{2,14,15}$. In the study of Park et al ${ }^{12}$, there were $22.6 \%$ subsidence and $9.7 \%$ nonunion. Yang et al. ${ }^{25}$ reported in their study of ACDF with stand-alone case filled with iliac crest bone graft that $25.5 \%$ subsidence and $14.9 \%$ nonunion. In a similar study by Bartels et al. ${ }^{2}$ in ACDF using a stand-alone cage packed with local autologous bone graft from the adjacent vertebrae found, $29.2 \%$ subsidence and $4.3 \%$ nonunion. Though there were risks of nonunion and subsidence in their study, early recovery, low complication rate and relatively good clinical outcomes were observed. In this present study, we perform ACDF in single level non-traumatic, degenerative cervical diseases using a stand-alone PEEK cage filled with local autologous bone from the osteophytes of both the vertebral bodies and lower anterior lip of the upper vertebral body of the corresponding segment. The purpose of this study was to assess the outcome of ACDF surgery using a standalone PEEK cage filled with local auto bone graft from adjacent segment of cervical spine both clinically and radiologically including fusion \& subsidence.

\section{Materials AND Methods}

\subsection{Patient Selection}

In this study, thirty six consecutive patients (20 males and 16 females) who were suffering from degenerative cervical disc disease with myelopathy or radiculopathy or both not improved by proper conservative treatment of adequate period were included. All of the patients underwent single level ACDF with stand-alone PEEK cage filled with autologous bone graft from adjacent segment vertebrae during the period from July 2015 to June 2017. The patients having previous or subsequent cervical spine surgery or with multilevel cervical spine surgery, cage packed with bone substitutes or allograft or autograft from iliac crest or additional cervical plating or patients suffering from traumatic spinal cord injury or any infectious disease of cervical spine were excluded from this study.

\subsection{Surgical Technique}

Under general anesthesia and patient was on supine position, ACDF was performed from the right side. Through a transverse skin incision, soft tissues were dissected. Then the disc was identified through fluoroscopic guidance and the discectomy was done. Lower anterior lip from the body of upper vertebra and osteophytes of lower \&upper vertebral bodies were carefully removed using a Kerrison punch and were collected. (Fig. 1A). Both the upper and lower endplates were carefully prepared without using the drill. A PEEK cage of appropriate size filled with those local autologous bone fragments were implanted in the disc space.(Fig. 1B).All of the patients after surgery were treated with a same protocol of rest and soft cervical collar for 6 weeks and then light physiotherapy.
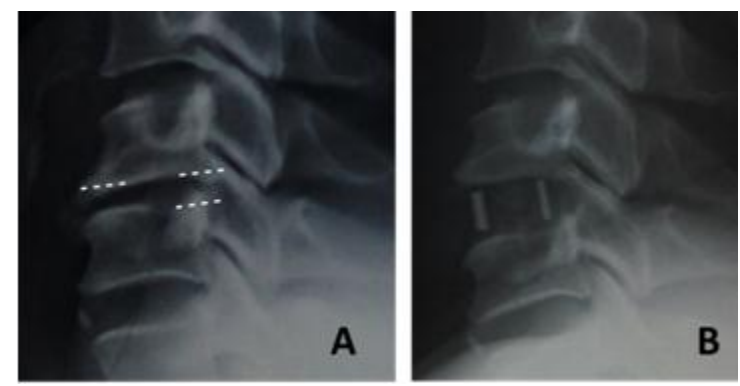

Figure1. (A)Preoperative $x$-ray of cervical spine: prominent posterior osteophytes and lower anterior lip, (B) postoperative $x$-ray of cervical spine: polyetheretherketone (PEEK) cage filled with local autologous bone graft from lower anterior lip from the body of upper vertebra and osteophytes of lower \& upper vertebral bodies was implanted.

\subsection{Clinical Evaluation}

The patients were clinically evaluated by VAS (Visual Analogue Scale) score, NDI (Neck Disability Index) and modified Odom's Criteria. Neck \& arm pain were assessed by using the Visual Analogue Scale (VAS) and functionality was evaluated using the Neck Disability Index (NDI). Overall clinical outcome finally was 
assessed by using Modified Odom's Criteria. The four grades of Modified Odom's Criteria were excellent outcome, good outcome, fair outcome, and poor outcome. Excellent was defined as the symptoms relieved completely and the patient was able to do all activities; good was defined when there was intermittent discomfort without interference in daily activities; Fair was defined when there was subjective improvement but impaired physical activity and poor was defined as there was no improvement or worse. ${ }^{2,16}$.

\subsection{Radiological Evaluation}

Radiological evaluations involved preoperative $\&$ postoperative plain radiography $\&$ functional radiography ${ }^{17}$. It included the preoperative and postoperative measurement of Interbody height\& Segmental angle and the occurrence of bone bridging anteriorly \& posteriorly at operated segment during final follow up. Interbody height (IBH) was defined as the distance in between the middle point of the upper end plate of the superior vertebral body and the middle point of the lower end plate of the inferior vertebral body (Fig. 2A). Segmental angle (SA) was defined as the angle between the lower end plate of the inferior vertebral body and the upper end plate of the superior vertebral body was measured by Cobb's method which (Fig. 2B). Reduction of the interbody height more than $2 \mathrm{~mm}$ in last follow up image from immediate post-operative image was defined as Subsidence. On last follow up, establishment of solid bony bridge at the fusion segment was defined as Solid bone fusion. On lateral flexion and extension radiographs, if the motion of less than $2^{\circ}$ without the movement between the spinous processes at the operated segment then it was rated as a solid arthrodesis ${ }^{1,2,8,13}$. On the other hand, movement of $\geq 2^{\circ}$ on dynamic radiographs (flexion \& extension posture) was rated as a pseudarthrosis ${ }^{2,18}$.

Table1. Segmental angle (SA) and Mean interbody height (IBH) during preoperative, immediate postoperative and final follow up

\begin{tabular}{|l|l|l|l|l|}
\hline & Preoperative & Immediate postoperative & Final follow-up & $p$ value \\
\hline Segmental angles (SA) & $4.16 \pm 0.61$ & $3.64 \pm 0.43$ & $3.98 \pm 0.42$ & 0.692 \\
\hline Interbody height (mm) (IBH) & $27.96 \pm 3.84$ & $29.87 \pm 3.78$ & $28.16 \pm 3.96$ & 0.221 \\
\hline
\end{tabular}

Among the thirty six patients, subsidence (reduction of the interbody height more than 2 $\mathrm{mm})$ was found in 9patients $(25 \%)$ and twentyseven patients $(75 \%)$ had without subsidence. Case subsidence between 2 to $3 \mathrm{~mm}$ found in 4 patients, between 3 to $4 \mathrm{~mm}$ found in 1 patient
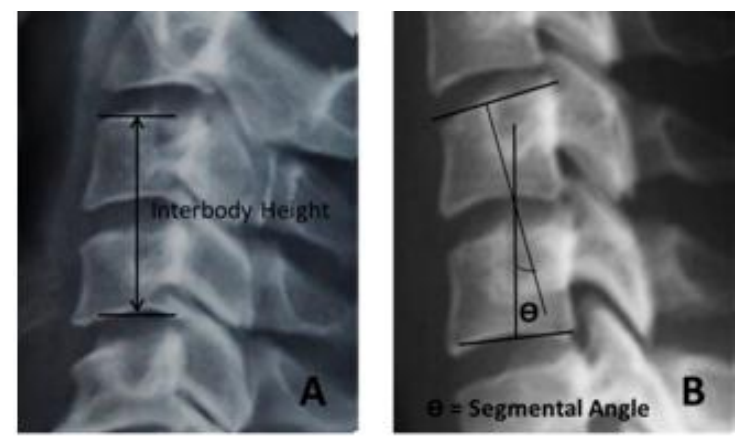

Figure2. (A)Interbody height (IBH): The distance in between the middle point of the upper end plate of the superior vertebral body and the middle point of the lower end plate of the inferior vertebral body. (B) Segmental angle (SA): The angle between the lower end plate of the inferior vertebral body and the upper end plate of the superior vertebral body (measured by Cobb's method)

\subsection{Statistical Analysis}

All the data were analyzed by using SPSS software and were reported as mean \pm standard deviations. The paired t-test was used to evaluate the interbody height and segmental angle in immediate postoperative and last follow up period. Two sided probability test was used (probability value $\leq 0.05$ was considered as statistically significant).

\section{RESUltS}

\subsection{Radiological Outcomes}

The Interbody height (IBH) and segmental angle (SA) were summarized on Table 1. Immediately after surgery, the mean IBH was $29.87 \pm 3.78$ and at last follow up, this value decreased to $28.16 \pm 3.96 \mathrm{~mm}$. The difference of Interbody height (IBH) between immediate post-operative period and the last follow up $(1.71 \pm 0.14 \mathrm{~mm})$ was not significant statistically. The mean segmental angle (SA) on immediate postoperative period was $3.64 \pm 0.43$ and at last follow-up was $3.98 \pm 0.42$ degrees. and subsidence greater than $4 \mathrm{~mm}$ found in 4 patients. Among nine patients of subsidence group, four patients had endplate damage during intraoperative endplate preparation. During the final follow up, out of 36 patients, 31 patients $(86.11 \%)$ achieved solid bone fusion but 
nonunion occurred in 5 patients (13.89\%). All of the twenty-seven patients without subsidence achieved complete fusion. But among the nine patients of subsidence group, 4 patients achieved fusion (44.6\%) whereas nonunion occurred in 5 patients (55.6\%). Among the subsidence group, all of the four patients with a subsidence of 2-3 mm were fused, but all of the patients with a subsidence of over $3 \mathrm{~mm}$ had nonunion. (Table2).

Table2. Outcomes of patients with subsidence and their demographics

\begin{tabular}{|c|c|c|c|c|c|c|c|c|c|c|}
\hline & \multirow{2}{*}{$\begin{array}{l}\text { Sex/ } \\
\text { age }\end{array}$} & \multirow[t]{2}{*}{ Level } & \multirow{2}{*}{$\begin{array}{l}\text { Odom's } \\
\text { criteria }\end{array}$} & \multirow{2}{*}{$\begin{array}{l}\text { Subsidence } \\
(\mathrm{mm})\end{array}$} & \multirow{2}{*}{$\begin{array}{l}\text { Last } \\
\text { Follow } \\
\text { up months }\end{array}$} & \multirow[t]{2}{*}{ fusion } & \multicolumn{2}{|l|}{ VAS } & \multicolumn{2}{|l|}{ NDI } \\
\hline & & & & & & & $\begin{array}{l}\text { Pre } \\
\text { oper. }\end{array}$ & $\begin{array}{l}\text { Post } \\
\text { oper. }\end{array}$ & $\begin{array}{l}\text { Pre } \\
\text { oper. }\end{array}$ & $\begin{array}{l}\text { Post } \\
\text { oper }\end{array}$ \\
\hline 1 & M/63 & C5-6 & Excellent & 5.6 & 12 & Nonunion & 8 & 1 & 8 & 1 \\
\hline 2 & $\mathrm{M} / 53$ & C3-4 & Good & 3.6 & 12 & Nonunion & 7 & 1 & 12 & 2 \\
\hline 3 & $\mathrm{M} / 48$ & C4-5 & Good & 5.7 & 12 & Nonunion & 7 & 3 & 15 & 3 \\
\hline 4 & $\mathrm{M} / 57$ & C4-5 & Excellent & 2.7 & 13 & Fusion & 8 & 2 & 16 & 6 \\
\hline 5 & $\mathrm{~F} / 64$ & C3-4 & Excellent & 4.1 & 12 & Nonunion & 7 & 1 & 19 & 3 \\
\hline 6 & $\mathrm{~F} / 61$ & C6-7 & Excellent & 4.3 & 10 & Nonunion & 6 & 1 & 20 & 11 \\
\hline 7 & $\mathrm{~F} / 61$ & C5-6 & Good & 2.1 & 12 & Fusion & 7 & 1 & 22 & 11 \\
\hline 8 & $\mathrm{~F} / 55$ & C5-6 & Good & 2.2 & 12 & Fusion & 6 & 2 & 18 & 7 \\
\hline 9 & M/62 & C6-7 & Excellent & 2.5 & 11 & Fusion & 9 & 1 & 22 & 13 \\
\hline
\end{tabular}

\subsection{Clinical Outcomes}

All of the thirty six patients improved clinically after surgery. The mean VAS pre-operatively was $6.57 \pm 1.68$ and during the final follow up was $1.72 \pm 1.21$. The mean NDI pre-operatively was $20.52 \pm 9.69$ and during the final follow up was 9.34 \pm 5.61 . Pre-operative VAS and NDI were decreased during the final follow up which was statistically significant.

Final outcome was evaluated by modified Odom's criteria. Excellent outcome was achieved in twenty $(55.6 \%)$ patients and sixteen (44.4\%) patients achieved good outcome. Among the patients with subsidence group, five patients had excellent and other four patients had good outcome. Though there was occurrence of nonunion or subsidence, additional surgery was not needed as the clinical outcomes of all of these patients were excellent or good.

\section{DISCUSSION}

Traditionally, autologous bone graft from iliac crest has been used to fill the disc space in ACDF surgery which have an excellent bony fusion rate with a good clinical outcome ${ }^{2}$, $7,15,18,19$. But due to its some donor site morbidities such as pain, numbness, and infection, stand-alone cage has become popular ${ }^{8}$, $9,13,18$. Though the stability, disc height restoration or facilitation of bone fusion have been reported as the effectiveness of stand-alone cage, nonunion \& subsidence are the stablished disadvantage of ACDF with stand-alone cages ${ }^{2}$, $4,8,20,21$.

A number of different types of cages and various materials to fill the cages are available with variable opinion and controversy ${ }^{1,5,8,22}$. Cancellous iliac bone chips are used by some surgeon to fill the cages. In a study by Vavruchet al. ${ }^{23}$ described that there was low fusion rate with a stand-alone case packed with the cancellous bone from iliac crest (62\%) compared with autologous iliac crest bone graft alone (86\%). Bartels et al. ${ }^{2,} 16$ reported in their study of ACDF with stand-alone cages filled with autologous cancellous bone from iliac crest and found that the incidence of nonunion \&subsidence were $29.2 \%$ \& $4.3 \%$ accordingly. Because of its low invasiveness, they recommend the stand-alone cage filled with cancellous bone from iliac crest in a standard ACDF procedure, but still there were morbidities like donor site pain, numbness or infections. To avoid these complications few authors tried to use empty cages, but use of empty cages was questionable in the point of fusion. In a study of anterior cervical discectomy with empty PEEK cages, Loannis et al. found a low fusion rate $^{11}$.Payer et al. ${ }^{10}$ performer a study of ACDF with empty carbon fiber cage and found $98 \%$ bone fusion rate and $20 \%$ subsidence over $2 \mathrm{~mm}$. Many authors reported the use of allobone and bone substitute in ACDF as filling material. But using bone substitute or allobone would need additional costs and has a risk of pathogen transmission $^{4,5}$.

In this study, local autologous bones from were collected to pack up the PEEK case. The local autologous bones were collected from the anterior osteophytes of the upper and lower vertebral bodies of the corresponding segment 
\& lower anterior lip of the upper body of vertebra.

Min et al. ${ }^{22}$ performed a study of osteogenic potentials of stem cells and found that the bone marrow ofiliac crest had same potential to those of the body of vertebral. So, to fill the cage, bony chips from body of vertebra would be a good alternative as graft material.

Shad et al. ${ }^{13}$ assessed clinical and radiological outcomes of a study of ACDF using drill to remove osteophytes and filled the case with this bone dust. In their study, there were relatively good clinical outcome with $77.2 \%$ cases had solid bone fusion which was lower than this study.

In the study of ACDF using local autobone grafts with anterior plate system, Pitzenet al. ${ }^{6}$ showed a good radiological outcomes and $91.3 \%$ fusion rate. In compare to their study, a similar bone fusion rate $(86.11 \%)$ along with good clinical outcomes was achieved without using the anterior plate system in this study.

Subsidence and nonunion have several risk factors $2,4,7,24,25$. As for examples, wrong surgical techniques such as over distraction, endplate damage, and inadequate preparation of endplate. Among the nine subsidence cases, four patients had end plate damage during the preparation of endplate in this study.

So, it would be an important factor not to damage the endplate cartilage to decrease subsidence during ACDF.

The incidence of subsidence by Bartels et al. ${ }^{2,16}$ was statistically higher at C6-7 levels. The orientation of C6-7 would cause the higher stress shielding in cervical spine which would be a possible reason of high incidence of subsidence at that level. However, only two of nine cases of subsidence occurred in at that level in this series.

In this study, age over 60 years was found among five of nine cases of subsidence group. Osteoporosis of vertebra could be a risk factor of subsidence though the bone mineral density could not be evaluate in all patients. Therefore, it should be checked for osteoporosis before surgery to predict or avoid the risk of subsidence.

Nonunion was found in five of nine patients where as rest of the four patients of subsidence group and all of the patients without subsidence achieved a good fusion. So, subsidence would be an important risk factor of nonunion. However all patients improved clinically by relieving from pain even in subsidence and nonunion group.

In this study, CT-scan was not done routinely to reduce the cost and to avoid unnecessary radiation exposure, though it might be a good alternative to know the precise statement of bony ingrowth.

\section{CONCLUSION}

The clinical outcomes and fusion rates are good enough in anterior cervical discectomy and fusion (ACDF) surgery with a stand-alone polyetheretherketone (PEEK) cage filled with local autologous bone from adjacent vertebral body compared with other methods, though it has the risk of subsidence. Using the autologous bone graft from the adjacent vertebral body reduces the morbidity and infection risk associated with allobone or bone substitutes or a second surgical site. In addition, use of local autologous bone graft should result in healing rates similar to other autograft sources.

So, it would be a good alternative in selected patients with adequate and careful endplate preparation, ACDF with stand-alone PEEK cages filled with local autologous bone from adjacent vertebral body to decrease donor site morbidity, early mobilization and additional costs required by other methods.

\section{REFERENCES}

[1] Ba Z, Zhao W, Wu D, Shen B, Yu B, Wang Z. Box cages packed with local decompression bone were efficient in anterior cervical discectomy and fusion: five- to 10-year followup. Spine. 2012; 37:1260-1263.

[2] Bartels RH, Donk RD, Feuth T. Subsidence of stand-alone cervical carbon fiber cages. Neurosurgery. 2006; 58:502-508.

[3] Cloward RB. The anterior approach for removal of ruptured cervical disks. J Neurosurg. 1958; 15:602-617.

[4] Ha SK, Park JY, Kim SH, Lim DJ, Kim SD, Lee SK. Radiologic assessment of subsidence in stand-alone cervical polyetheretherketone (PEEK) cage. J Korean Neurosurg Soc. 2008; 44:370-374.

[5] Kaiser MG, Haid RW, Jr, Subach BR, Barnes B, Rodts GE., Jr Anterior cervical plating enhances arthrodesis after discectomy and fusion with cortical allograft. Neurosurgery. 2002; 50:229-236. discussion 236-238.

[6] Pitzen T, Kiefer R, München D, Barbier D, Reith W, Steudel WI. Filling a cervical spine 
cage with local autograft: change of bone density and assessment of bony fusion. ZentralblNeurochir. 2006;67: 8-13

[7] Smith GW, Robinson RA. The treatment of certain cervical-spine disorders by anterior removal of the intervertebral disc and interbody fusion. J Bone Joint Surg Am. 1958; 40:607624.

[8] Lee CH, Hyun SJ, Kim MJ, Yeom JS, Kim $\mathrm{WH}$, Kim KJ, et al. Comparative analysis of 3 different construct systems for single-level anterior cervical discectomy and fusion: standalone cage, iliac graft plus plate augmentation, and cage plus plating. J Spinal Disord Tech. 2013; 26:112-118.

[9] Peelle MW, Rawlins BA, Frelinghuysen P. A novel source of cancellous autograft for ACDF surgery: the manubrium. J Spinal Disord Tech. 2007; 20:36-41.

[10] Payer M, May D, Reverdin A, Tessitore E. Implantation of an empty carbon fiber composite frame cage after single-level anterior cervical discectomy in the treatment of cervical disc herniation: preliminary results. J Neurosurg. 2003; 98:143-148.

[11] Pechlivanis I, Thuring T, Brenke C, Seiz M, Thome C, Barth M, et al. Non-fusion rates in anterior cervical discectomy and implantation of empty polyetheretherketone cages. Spine 2011; 36:15-20.

[12] Park J, Cho DC, Kim KT, Sung JK. Anterior Cervical Discectomy and Fusion Using a Stand-Alone Polyetheretherketone Cage Packed with Local Autobone: Assessment of Bone Fusion and Subsidence. J Korean Neurosurg Soc. 2013; 54:189-193.

[13] Shad A, Leach JC, Teddy PJ, Cadoux-Hudson TA. Use of the Solis cage and local autologous bone graft for anterior cervical discectomy and fusion: early technical experience. J Neurosurg Spine. 2005; 2:116-122.

[14] Kulkarni AG, Hee HT, Wong HK. Solis cage (PEEK) for anterior cervical fusion: preliminary radiological results with emphasis on fusion and subsidence. Spine J. 2007; 7:205-209.

[15] Kast E, Derakhshani S, Bothmann M, Oberle J. Subsidence after anterior cervical inter-body fusion. A randomized prospective clinical trial. Neurosurg Rev. 2009; 32:207-214.

[16] Bartels RH, Donk R, van Azn RD. Height of cervical foramina after anterior discectomy and implantation of a carbon fiber cage. J Neurosurg. 2001; 95:40-42.

[17] Cabraja M, Oezdemir S, Koeppen D, Kroppenstedt S. Anterior cervical discectomy and fusion: Comparison of titanium and polyetheretherketone cages. BMC Musculoskeletal Disorders. 2012; 13:172.

[18] Banwart JC, Asher MA, Hassanein RS. Iliac crest bone graft harvest donor site morbidity. A statistical evaluation. Spine. 1995; 20:10551060.

[19] Castro FP, Jr, Holt RT, Majd M, Whitecloud TS., 3rd A cost analysis of two anterior cervical fusion procedures. J Spinal Disord. 2000; 13:511-514.

[20] Barsa P, Suchomel P. Factors affecting sagittal malalignment due to cage subsidence in standalone cage assisted anterior cervical fusion. Eur Spine J. 2007; 16:1395-1400.

[21] Fürderer S, Schöllhuber F, Rompe JD, Eysel P. Effect of design and implantation technique on risk of progressive sintering of various cervical vertebrae cages. Orthopade. 2002; 31:466-471.

[22] Min WK, Bae JS, Park BC, Jeon IH, Jin HK, Son MJ, et al. Proliferation and osteoblastic differentiation of bone marrow stem cells: comparison of vertebral body and iliac crest. Eur Spine J. 2010; 19:1753-1760.

[23] Vavruch L, Hedlund R, Javid D, Leszniewski W, Shalabi A. A prospective randomized comparison between the cloward procedure and a carbon fiber cage in the cervical spine: a clinical and radiologic study. Spine. 2002; 27:1694-1701.

[24] vanJonbergen HP, Spruit M, Anderson PG, Pavlov PW. Anterior cervical interbody fusion with a titanium box cage: early radiological assessment of fusion and subsidence. Spine J. 2005; 5:645-649.

[25] Yang JJ, Yu CH, Chang BS, Yeom JS, Lee JH, Lee CK. Subsidence and nonunion after anterior cervical interbody fusion using a standalone polyetheretherketone (PEEK) cage. ClinOrthop Surg. 2011; 3:16-23.

Citation: Mohammad Nuruzzaman Khan, Sabrina Shafiq, Saumitra Sarkar. Anterior Cervical Discectomy and Fusion (ACDF) using Stand-Alone Polyetheretherketone (PEEK) Cage Packed with Local Autologous Bone Graft. ARC Journal of Cancer Science 2018; 4(1):18-23. DOI: http://dx.doi.org/10.20431/24556009.0401005

Copyright: (C) 2018 Authors. This is an open-access article distributed under the terms of the Creative Commons Attribution License, which permits unrestricted use, distribution, and reproduction in any medium, provided the original author and source are credited. 